Louisiana State University

LSU Digital Commons

Faculty Publications

Department of Biological Sciences

7-7-2006

\title{
The importance of demographic niches to tree diversity
}

\author{
Richard Condit \\ National Center for Ecological Analysis and Synthesis \\ Peter Ashton \\ Harvard University \\ Sarayudh Bunyavejchewin \\ National Park, Wildlife and Plant Conservation Department, Thailand \\ H. S. Dattaraja \\ Indian Institute of Science, Bengaluru \\ Stuart Davies \\ Harvard University
}

See next page for additional authors

Follow this and additional works at: https://digitalcommons.Isu.edu/biosci_pubs

\section{Recommended Citation}

Condit, R., Ashton, P., Bunyavejchewin, S., Dattaraja, H., Davies, S., Esufali, S., Ewango, C., Foster, R., Gunatilleke, I., Gunatilleke, C., Hall, P., Harms, K., Hart, T., Hernandez, C., Hubbell, S., Itoh, A., Kiratiprayoon, S., LaFrankie, J., Loo De Lao, S., Makana, J., Noor, M., Kassim, A., Russo, S., Sukumar, R., Samper, C., Suresh, H., Tan, S., Thomas, S., Valencia, R., Vallejo, M., Villa, G., \& Zillio, T. (2006). The importance of demographic niches to tree diversity. Science, 313 (5783), 98-101. https://doi.org/10.1126/ science. 1124712

This Article is brought to you for free and open access by the Department of Biological Sciences at LSU Digital Commons. It has been accepted for inclusion in Faculty Publications by an authorized administrator of LSU Digital Commons. For more information, please contact ir@lsu.edu. 


\section{Authors}

Richard Condit, Peter Ashton, Sarayudh Bunyavejchewin, H. S. Dattaraja, Stuart Davies, Shameema Esufali, Corneille Ewango, Robin Foster, I. A.U.N. Gunatilleke, C. V.S. Gunatilleke, Pamela Hall, Kyle E. Harms,

Terese Hart, Consuelo Hernandez, Stephen Hubbell, Akira Itoh, Somboon Kiratiprayoon, James LaFrankie, Suzanne Loo De Lao, Jean Remy Makana, Md Nur Supardi Noor, Abdul Rahman Kassim, Sabrina Russo,

Raman Sukumar, Cristián Samper, Hebbalalu S. Suresh, Sylvester Tan, Sean Thomas, Renato Valencia, Martha Vallejo, Gorky Villa, and Tommaso Zillio 
University of Nebraska - Lincoln

DigitalCommons@University of Nebraska - Lincoln

Faculty Publications in the Biological Sciences

Papers in the Biological Sciences

7-7-2006

\title{
The Importance of Demographic Niches to Tree Diversity
}

\author{
Richard Condit \\ Smithsonian Tropical Research Institute, condit@ctfs.si.edu \\ Peter Ashton \\ Harvard University \\ Sarayudh Bunyavejchewin \\ Thai National Park Wildlife and Plant Conservation Department \\ H. S. Dattaraja \\ Indian Institute of Science, Bangalore
}

Stuart J. Davies

Harvard University, daviess@si.edu

See next page for additional authors

Follow this and additional works at: https://digitalcommons.unl.edu/bioscifacpub

Part of the Life Sciences Commons

Condit, Richard; Ashton, Peter; Bunyavejchewin, Sarayudh; Dattaraja, H. S.; Davies, Stuart J.; Esufali, Shameema; Ewango, Corneille; Foster, Robin; Gunatilleke, I. A.U.N.; Gunatilleke, C. V.S.; Hall, Pamela; Harms, Kyle E.; Hart, Terese; Hernandez, Consuelo; Hubbell, Stephen; Ito, Akira; Kiratiprayoon, Somboon; LaFrankie, James; Loo de Lao, Suzanne; Makana, Jean-Remy; Noor, Md. Nur Supardi; Kassim, Abdul Rahman; Russo, Sabrina E.; Sukumar, Raman; Samper, Cristián; Suresh, Hebbalulu S.; Tan, Sylvester; Thomas, Sean; Valencia, Renato; Vallejo, Martha; Villa, Gorky; and Zillio, Tommaso, "The Importance of Demographic Niches to Tree Diversity" (2006). Faculty Publications in the Biological Sciences. 230. https://digitalcommons.unl.edu/bioscifacpub/230

This Article is brought to you for free and open access by the Papers in the Biological Sciences at DigitalCommons@University of Nebraska - Lincoln. It has been accepted for inclusion in Faculty Publications in the Biological Sciences by an authorized administrator of DigitalCommons@University of Nebraska - Lincoln. 


\section{Authors}

Richard Condit, Peter Ashton, Sarayudh Bunyavejchewin, H. S. Dattaraja, Stuart J. Davies, Shameema Esufali, Corneille Ewango, Robin Foster, I. A.U.N. Gunatilleke, C. V.S. Gunatilleke, Pamela Hall, Kyle E. Harms, Terese Hart, Consuelo Hernandez, Stephen Hubbell, Akira Ito, Somboon Kiratiprayoon, James LaFrankie, Suzanne Loo de Lao, Jean-Remy Makana, Md. Nur Supardi Noor, Abdul Rahman Kassim, Sabrina E. Russo, Raman Sukumar, Cristián Samper, Hebbalulu S. Suresh, Sylvester Tan, Sean Thomas, Renato Valencia, Martha Vallejo, Gorky Villa, and Tommaso Zillio 


\section{REPORTS}

\section{The Importance of Demographic Niches to Tree Diversity}

Richard Condit, ${ }^{1,2^{*}}$ Peter Ashton, ${ }^{3}$ Sarayudh Bunyavejchewin, ${ }^{4}$ H. S. Dattaraja, ${ }^{5}$ Stuart Davies, ${ }^{3}$ Shameema Esufali, ${ }^{6}$ Corneille Ewango, ${ }^{7}$ Robin Foster, ${ }^{8}$ I. A. U. N. Gunatilleke, ${ }^{6}$ C. V. S. Gunatilleke, ${ }^{6}$ Pamela Hall, ${ }^{9}$ Kyle E. Harms, ${ }^{10}$ Terese Hart, ${ }^{11}$ Consuelo Hernandez, ${ }^{12}$ Stephen Hubbell, ${ }^{13}$ Akira Itoh, ${ }^{14}$ Somboon Kiratiprayoon, ${ }^{15}$ James LaFrankie, ${ }^{16}$ Suzanne Loo de Lao, ${ }^{2}$ Jean-Remy Makana, ${ }^{11}$ Md. Nur Supardi Noor, ${ }^{17}$ Abdul Rahman Kassim, ${ }^{17}$ Sabrina Russo, ${ }^{3}$ Raman Sukumar, ${ }^{5}$ Cristián Samper, ${ }^{18}$ Hebbalalu S. Suresh, ${ }^{5}$ Sylvester Tan, ${ }^{19}$ Sean Thomas,${ }^{20}$ Renato Valencia, ${ }^{12}$ Martha Vallejo, ${ }^{21}$ Gorky Villa, ${ }^{12}$ Tommaso Zillio ${ }^{1,2}$

Most ecological hypotheses about species coexistence hinge on species differences, but quantifying trait differences across species in diverse communities is often unfeasible. We examined the variation of demographic traits using a global tropical forest data set covering 4,500 species in 10 large-scale tree inventories. With a hierarchical Bayesian approach, we quantified the distribution of mortality and growth rates of all tree species at each site. This allowed us to test the prediction that demographic differences facilitate species richness, as suggested by the theory that a tradeoff between high growth and high survival allows species to coexist. Contrary to the prediction, the most diverse forests had the least demographic variation. Although demographic differences may foster coexistence, they do not explain any of the 16-fold variation in tree species richness observed across the tropics.

Comparative studies of tree demography typically consider the entire community as a unit, ignoring species differences (1), simply because most tree inventories include small samples of many species $(2,3)$. Comparative studies show that tropical forests typically have higher turnover than do temperate forests (4) and that higher tree turnover associates with higher tree diversity (5). These studies cannot, however, test ecological hypotheses about diversity, coexistence, and demography (6-10).

A tradeoff between rapid growth and long life span permits species coexistence and can foster diversity: Species reproducing early in life persist despite poor competitive ability by growing rapidly on disturbed sites where resources are abundant. Longlived species coexist by outliving the weedy invaders, persisting where resources are scarce. This is a familiar and widely known tradeoff in plant and animal communities (9-11) called the successional-niche hypothesis $(7,12)$. At a deterministic equilibrium, an indefinite number of species can coexist by this mechanism, each differing from all others along a continuum from short life span (with high growth) to long life span (and low growth). With stochastic demography, however, there is limiting similarity and the equilibrium species richness is finite $(11,13)$. This hypothesis is widely quoted as an explanation for tropical forest diversity (14-16). Here, we ask whether species differences along a demographic axis explain why some tropical forests have many more species than others.

If demographic niches are a key force controlling forest diversity, then more diverse forests have more demographic niches. More niches could come about either by spreading demographic rates over a wider range or packing more in the same range. Here, we focus on the first prediction: Tropical forests gain diversity by having a wider range of demographic niches, as reflected by the range of mortality and growth rates across species.

We provide a direct test by quantifying mortality and growth of 4,500 tree species in 10 different forests in America, Asia, and Africa (17). The 10 sites form a large-scale observation program, spanning a wide range of environmental conditions, designed to provide species-specific information for little-known tropical trees (18). At each site, a 20- to 52-ha tree census was set out in extensive, largely undisturbed forest (table S1). Species richness within the census plots differed by 16 -fold, from 73 species per 50 ha in a dry forest at Mudumalai, India, to 1,167 species per 50 ha in a wet dipterocarp forest in Sarawak, Malaysia (19).

Past studies on the demography of individual tree species were based on direct measures of rate constants. These excluded many rare species because their rate estimates are subject to high error $(20,21)$. To overcome this limitation, we did not simply record species' rates of mortality and growth; instead, we quantified the distribution of demographic rates across the entire community. A hierarchical Bayesian approach accomplishes this with explicit probability models covering both the observations of individual trees within species and the variation among species; all species, including rare ones, are included. For mortality, within-species distributions were modeled with the binomial distribution; for growth, we chose the log-normal based on the tendency for individual growth rates within a species to be highly skewed to the right. By separating within-species variation, the hierarchical model allows focus on the question of how species differ $(10,22$, 23).

At the community level, we had to describe the variation in species' demographic rates across species, and again, we used the log-normal to account for the skew to the right. Histograms of mortality rate $m$ and growth rate $g$ (24) are fitted well by the lognormal when rare species are excluded (Figure 1). The log-normal requires two parameters, $\mu$ and $\sigma$, the mean and standard deviation of the natural logarithm of $m$ or $g$, respectively. We were able to estimate values of $\mu$ and $\sigma$ that best describe a community's demography with the use of the Gibbs sampler, simultaneously producing for every species estimates of mortality and growth rates that are adjusted for abundance. That is, for abundant species, the estimate is barely different from the observed rate, but for rare species, it is guided by the communitywide pattern (25).

Fitted log-normal distributions for the Lambir forest in Malaysia are plotted with observed histograms of sapling mortality and growth (Figure 1). The fit is close for more common species (filled bars), demonstrating that the large number of zeroes in the mortality histogram are sampling arti-

${ }^{1}$ National Center for Ecological Analysis and Synthesis, Santa Barbara, California, U.S.A. ${ }^{2}$ Center for Tropical Forest Science, Smithsonian Tropical Research Institute, APO AA, U.S.A. ${ }^{3}$ Center for Tropical Forest Science, Asia Program, Arnold Arboretum Asia Program, Harvard University Herbaria, Cambridge, Massachusetts, U.S.A. ${ }^{4}$ Thai National Park Wildlife and Plant Conservation Department, Research Office, Chatuchak, Bangkok, Thailand. ${ }^{5}$ Center for Ecological Sciences, Indian Institute of Science, Bangalore, India. ${ }^{6}$ Department of Botany, Faculty of Science, University of Peradeniya, Peradeniya, Sri Lanka. ${ }^{7}$ University of Missouri, St. Louis, Missouri, U.S.A. ${ }^{8}$ Botany Department, Field Museum, Chicago, Illinois, U.S.A. ${ }^{9}$ Department of Biology, Florida State University, Tallahassee, Florida, U.S.A. ${ }^{10}$ Department of Biological Sciences, Louisiana State University, Baton Rouge, Louisiana, U.S.A. ${ }^{11}$ Wildlife Conservation Society, Ngalinema, Kinshasa I, Democratic Republic of Congo. ${ }^{12}$ Pontifícia Universidad Católica de Ecuador, Quito, Ecuador. ${ }^{13}$ Department of Plant Sciences, University of Georgia, Athens, Georgia, U.S.A. ${ }^{14}$ Plant Ecology Lab, Faculty of Science, Osaka City University, Sumiyoshi-ku, Osaka, Japan. ${ }^{15}$ Faculty of Science and Technology, Thammasat University (Rangsit), Klongluang, Patumtani, Thailand. ${ }^{16}$ Center for Tropical Forest Science, Asia Program, National Institute of Education, Nanyang Technological University, Singapore. ${ }^{17}$ Forest Environment Division, Forest Research Institute Malaysia, Kepong, Kuala Lumpur, Malaysia. ${ }^{18}$ National Museum of Natural History, Smithsonian Institution, Washington, D.C., U.S.A. ${ }^{19}$ Forest Research Center, Sarawak Forest Department, Kuching, Sarawak, Malaysia. ${ }^{20}$ University of Toronto, Toronto, Ontario, Canada. ${ }^{21}$ Instituto Alexander von Humboldt, Bogotá, Colombia.

*To whom correspondence should be addressed: condit@ctfs.si.edu 
facts in rare species. Growth rates are also spread by rare species, though not as conspicuously. Fitted distributions for all the forests can be compared graphically (Figure 2) or with estimated 2.5 and 97.5 percentiles (Table 1). In the supporting online material, tables of mortality and growth rates for all species are provided (database S1).

Most of the forests were dominated by species with sapling mortality rates near 1\% year $^{-1}$ (Figure 2). Even the high-mortality forests, such as Barro Colorado Island (BCI) and Hua Khae Khaeng National Park (HKK), had modes close to $1 \%$ year ${ }^{-1}$ and low rates around $0.4 \%$ year $^{-1}$. The main feature separating these high-rate forests from the lowrate sites (such as Pasoh in Malaysia) is the long tail reaching $20 \%$ year $^{-1}$ mortality; at Pasoh, nearly all species had mortality rates of $<3 \%$ year $^{-1}$. Thus, forests fell broadly in two groups: BCI, HKK, and La Planada had upper sapling mortality rates above $20 \%$, whereas Sinharaja, Lambir, Pasoh, and Yasuni had upper rates below $8 \%$. The Congo sites had exceedingly low mortality stretching to a modest $10 \%$ at the upper end.

Distributions of growth rates were similar to distributions of mortality, but growth was about half as variable across species (Figure 2). Conspicuously, sites with less variation in mortality also had less variation in growth (Figure 3). These patterns held for larger trees, although mortality and growth rates were lower (Table S2 and Figure S1).

Examples from individual species help illustrate. At BCI, a fast-growing understory treelet, Palicourea guianensis, had a population of 376 saplings in 1982, and every single one had died by 2005 (nevertheless, the population grew to 851). Although Palicourea's mor- tality rate is infinite by direct calculation, the Gibbs sampler produces an estimate of $33 \%$ year $^{-1}$. Alloplectus schultzei, a small, weedy treelet at La Planada, also suffered $33 \%$ year${ }^{1}$ mortality, losing 284 of 335 individuals over 6 years. In contrast, of 1,161 species at Lambir, none had mortality of $30 \%$ year $^{-1}$, and only two had rates above $20 \%$; at Pasoh between 1987 and 2000, the very highest Gibbscorrected mortality rate among 802 species was $14 \%$ year-1, in Melastoma malabathricum. At the other end of the distribution, $\mathrm{Cu}$ pania sylvatica, a midsized tree of the BCI understory, lost only 10 of 1,102 individuals between 1990 and $1995\left(0.23 \%\right.$ year $\left.{ }^{-1}\right)$, and Carapa guianensis at La Planada, a large and valuable timber tree, lost only 11 of 894 $\left(0.28 \%\right.$ year $\left.^{-1}\right)$. In three census intervals at Pasoh, the lowest mortality rate recorded was $0.34 \%$ year $^{-1}$, in Cynometra malaccensis.
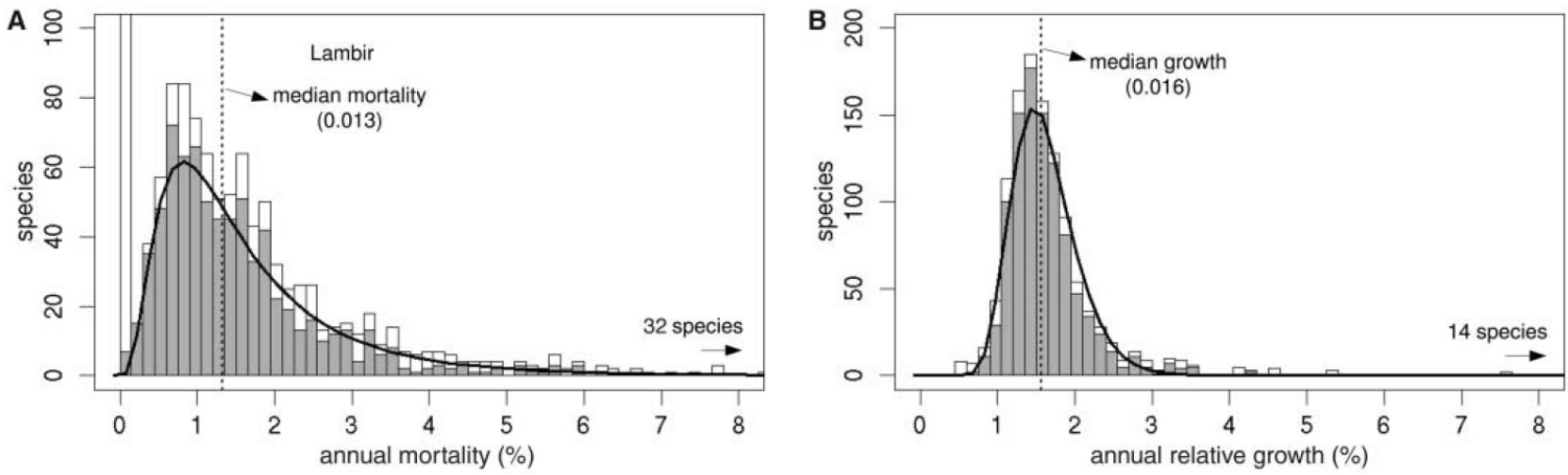

Figure 1. Distribution of sapling demographic rates of all species in the Lambir plot. (A) Annual mortality, $m$, for all individuals with $d b h=10$ to $99 \mathrm{~mm}$. Filled bars show the histogram of observed mortality rates for the 746 species with $\geq 50$ individuals; open bars add the 415 species with $<50$ individuals. The open bar at $m=$ 0 extends off the graph ( 162 species had no mortality; 6 of these had $<50$ individuals). The horizontal axis is $m$, expressed as a percent. The solid line is the fitted log-normal, based on all 1,161 species. The dashed vertical line indicates the mean of the logarithm of the fitted distribution (parameter $\mu$, Table 1), which is very close to the median. (B) Annual growth, $g$, for individuals 10 to $49 \mathrm{~mm}$ in diameter. Filled bars are the histogram for 995 species with $\geq 10$ individuals; open bars for the remaining 154 species. The solid curve and dashed line are the fitted log-normal and the mean of the logarithm, respectively, as in (A). Both histograms are curtailed at $8 \%$ to accentuate details where most of the species fall. The number of species above $8 \%$ is indicated by arrows.
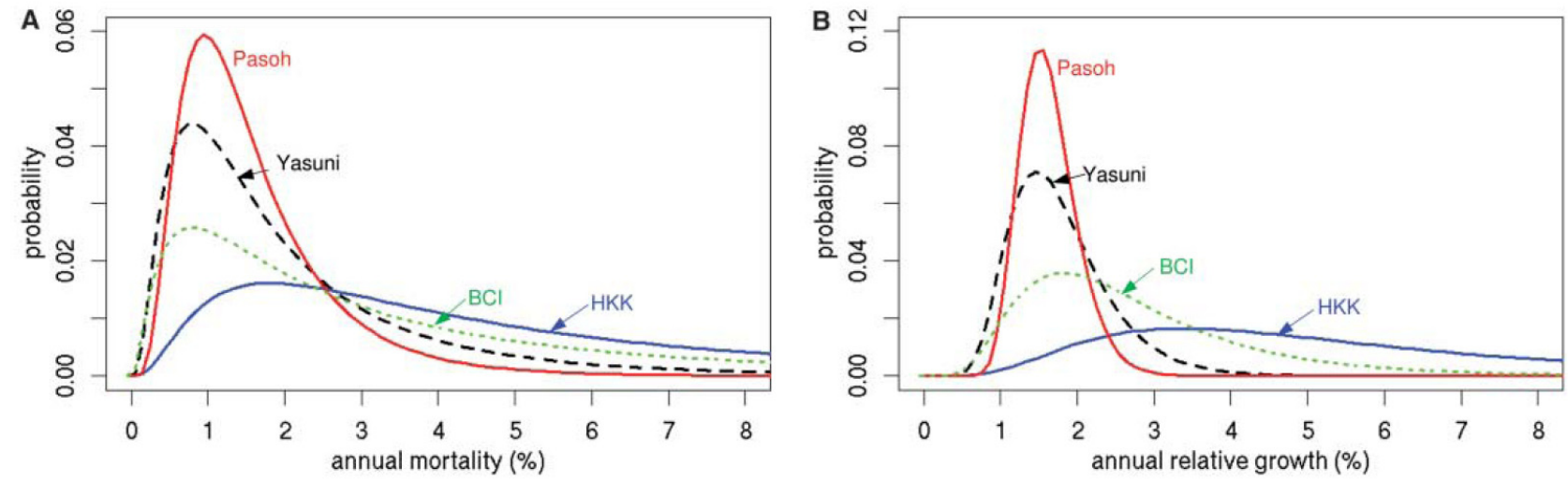

Figure 2. Comparing the fitted distributions of sapling demography in four forests. (A) Annual mortality rate, $m$. (B) Annual growth rate, $g$. The lower end of the growth distribution in saplings is limited by measurement accuracy (30). 
The Mudumalai forest stood out. Saplings had greatly elevated mortality and growth, with rates stretching much higher than any other site. Between 1988 and 1992, every species at Mudumalai had sapling growth of $>6 \%$ year ${ }^{-1}$, and only BCI and HKK had many rates this high. At Lenda and Sinharaja, no species grew by $6 \%$ year-1. For larger trees ( $\geq 100 \mathrm{~mm}$ diameter), however, Mudumalai was in line with other forests, having modes of mortality and growth near $1 \%$ year $^{-1}$ (table S2). Indeed, trees at Mudumalai had among the lowest rates as well as the highest: Anogeissus latifolia had 116 deaths out of 2,179 trees from 1988 to 2000, whereas Kydia calycina had 1,272 of 1,328 trees die over the same interval, many because of el50-fold: $27 \%$ year- $^{-1}$ in Kydia compared with $0.47 \%$ year $^{-1}$ in Anogeissus.

Three of the sites with long tails of elevated mortality and growth-BCI, HKK, and Mudumalai-have intense annual dry seasons (table S1). Mudumalai and HKK also burn in some years (26) (other plots do not burn and none suffer large-scale wind damage). It was not surprising that annual ephant herbivory (26). Their rates differ by

drought elevated mortality. Many species at these sites, however, had exceedingly low rates of mortality and evidently did not suffer much from drought. Conversely, forests lacking the tail of high growth and mortality had no or modest annual dry seasons, including the three forests dominated by Dipterocarpaceae (Sinharaja, Pasoh, and Lambir). Seasonality, however, was not the only factor predicting high variation in demography; the ever-wet cloud forest at La Planada, Colombia, had a wide spread of growth and mortality, comparable to the seasonally dry sites.

Mudumalai and HKK have relatively open canopies compared with all of the other sites, a typical feature of dry forests, and many saplings at Mudumalai are sprouts from large root systems. These are likely reasons for elevated sapling growth at the two sites. In contrast, both BCI and La Planada have dense canopies and dark understories, so canopy openness does not obviously account for the high-growth species at those two sites.

Contrary to the prediction that demographic variability begets species richness,

Figure 3. Range of sapling demographic rates for tree species within a community versus the number of species at the site. The range is the logarithm of the ratio between the 97.5 and 2.5 percentiles of the fitted distributions (Table 1). The range for mortality is given by filled circles; the range for growth is given by open triangles. Sites can be identified by the number of species; for example, Lambir is the most diverse and farthest to the right. Multiple censuses at BCI, Pasoh, and Mudumalai are included, and in each case, fall in a tight group.

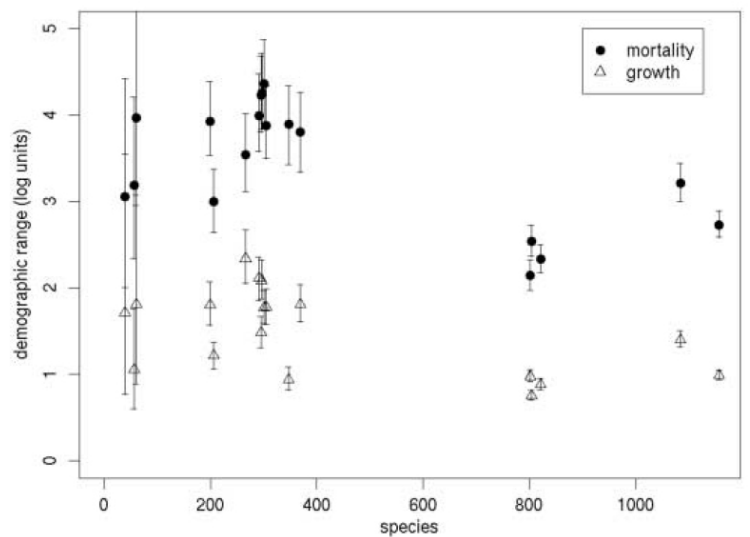

diverse forests had the least variation in demography (Figure 3 and Figure S1). If anything, the most diverse forests had the fewest demographic niches. At Lambir, high species richness coupled with a low diversity of demographic rates meant that 135 tree species coexisting in close proximity had sapling mortality rates in a narrow window from 0.8 to $1.0 \%$ year $^{-1}$.

We do not question that demographic variability plays some role in species coexistence. In American forests, the familiar genus Cecropia is found exclusively in small forest clearings (or outside the forest), where it rapidly colonizes and rapidly dies. The upper end of sapling mortality and growth distributions in America is set by gap specialists: C. obtusifolia at BCI (12\% year ${ }^{-1}$ mortality, $14 \%$ year $^{-1}$ growth), C. sciadophylla at Yasuni (5.0\% year ${ }^{-1}$ mortality, 6.3\% year ${ }^{-1}$ growth), and C. monostachya at La Planada (8.8\% year ${ }^{-1}$ mortality, $8.2 \%$ year ${ }^{-1}$ growth). Diverse Southeast Asian forests lacked species with such high rates (27).

The most diverse tropical forests are the least diverse demographically. It remains plausible that demographic niches are packed more tightly in some forests than others, but this seems unlikely, because packing should depend only on population size and turnover, which do not vary much. Moreover, the successional-niche hypothesis is not favored by the strong peak in demographic rates near 1 to $2 \%$ year $^{-1}$; if demographic niches were crucial, then rates ought to be spread evenly over the entire range (28). Instead, the similarity in demography of many species suggests trait convergence (29). We believe that broad diversity differences are due to the source pool of different biogeographic regions, and that demographic differences play a minor role in species coexistence.

Table 1. Variation in sapling mortality and growth rates across species in tropical forests. For mortality, all individuals with $d b h=10$ to 99 mm were included; for growth, those with $d b h=10$ to $49 \mathrm{~mm}$ were included. Species number refers to those with at least one 10-to 99-mm sapling alive at the outset of a given census interval. Under mortality are percentiles of the distribution of mortality rate parameters $(m)$ across species: the median plus lower and upper percentiles (2.5 and 97.5) of the fitted log-normal. Similarly, under growth are percentiles for the distribution of growth rates ( $g$ ) across species. Rates are expressed as percentages $(100 m$ or $100 g)$ - that is, $5=5 \%=0.05$. For each of the percentiles, confidence limits are given, based on the Gibbs sampler (25). Information about the sites is presented in table $\mathrm{S} 1$.

$\begin{array}{ll}\text { Site } & \text { Years } \\ & \\ \text { BCI } & 82-85 \\ \text { BCI } & 85-90 \\ \text { BCI } & 90-95 \\ \text { BCI } & 95-00 \\ \text { BCI } & 00-05 \\ \text { Yasuni } & 96-03 \\ \text { La Planada } & 97-03 \\ \text { Pasoh } & 87-90 \\ \text { Pasoh } & 90-95 \\ \text { Pasoh } & 95-00 \\ \text { Lambir } & 92-97 \\ \text { HKK } & 93-99 \\ \text { Mudumalai } & 88-92 \\ \text { Mudumalai } & 92-96 \\ \text { Mudumalai } & 96-00 \\ \text { Sinharaja } & 95-01 \\ \text { Edoro } & 94-00 \\ \text { Lenda } & 94-00\end{array}$

$\begin{array}{cc}\text { No. of species } & \text { Median } \\ & 3.14 \pm 0.46 \\ 284 & 2.56 \pm 0.37 \\ 282 & 2.85 \pm 0.43 \\ 282 & 3.35 \pm 0.42 \\ 285 & 2.91 \pm 0.41 \\ 285 & 1.55 \pm 0.10 \\ 1,077 & 3.22 \pm 0.47 \\ 218 & 1.04 \pm 0.06 \\ 802 & 1.35 \pm 0.07 \\ 801 & 1.69 \pm 0.09 \\ 804 & 1.32 \pm 0.07 \\ 1,161 & 4.11 \pm 0.57 \\ 256 & 13.06 \pm 3.48 \\ 56 & 17.06 \pm 6.43 \\ 52 & 7.96 \pm 2.70 \\ 39 & 1.35 \pm 0.17 \\ 205 & 1.43 \pm 0.20 \\ 368 & 1.26 \pm 0.19 \\ 346 & \end{array}$

Annual mortality (\%)

$\begin{array}{cr}\text { Lower } & \text { Upper } \\ 0.38 \pm 0.10 & 26.0 \pm 6.9 \\ 0.31 \pm 0.08 & 21.5 \pm 5.5 \\ 0.32 \pm 0.09 & 25.3 \pm 6.7 \\ 0.48 \pm 0.11 & 23.3 \pm 5.7 \\ 0.40 \pm 0.10 & 21.4 \pm 5.5 \\ 0.31 \pm 0.04 & 7.7 \pm 0.9 \\ 0.45 \pm 0.13 & 22.9 \pm 5.9 \\ 0.36 \pm 0.04 & 3.0 \pm 0.3 \\ 0.42 \pm 0.05 & 4.3 \pm 0.4 \\ 0.47 \pm 0.06 & 6.0 \pm 0.6 \\ 0.34 \pm 0.03 & 5.2 \pm 0.4 \\ 0.70 \pm 0.19 & 24.1 \pm 6.6 \\ 2.65 \pm 1.42 & 64.4 \pm 36 \\ 2.35 \pm 1.51 & 124 \pm 113 \\ 1.73 \pm 1.13 & 36.6 \pm 25 \\ 0.30 \pm 0.07 & 6.0 \pm 1.3 \\ 0.21 \pm 0.06 & 9.6 \pm 2.5 \\ 0.18 \pm 0.06 & 8.8 \pm 2.2\end{array}$

$0.18 \pm 0.06$

Relative growth (\%)

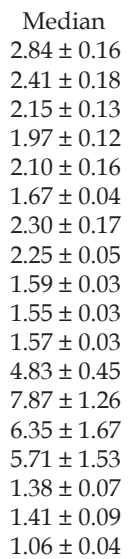

Lower $1.35 \pm 0.14$

$0.85 \pm 0.12$

$0.89 \pm 0.09$

$0.81 \pm 0.09$

$0.73 \pm 0.10$

$0.83 \pm 0.04$

$0.93 \pm 0.13$

$1.38 \pm 0.05$

$1.02 \pm 0.04$

$1.07 \pm 0.03$

$0.96 \pm 0.03$

$1.53 \pm 0.26$

$4.65 \pm 1.52$

$2.57 \pm 1.38$

$2.42 \pm 1.69$

$0.75 \pm 0.07$

$0.57 \pm 0.07$

$0.66 \pm 0.05$
Upper
$6.0 \pm 0.7$
$6.8 \pm 1.0$
$5.2 \pm 0.7$
$4.8 \pm 0.6$
$6.1 \pm 0.9$
$3.4 \pm 0.2$
$5.7 \pm 0.8$
$3.7 \pm 0.2$
$2.5 \pm 0.1$
$2.3 \pm 0.1$
$2.6 \pm 0.1$
$15.2 \pm 2.7$
$13.3 \pm 3.8$
$15.7 \pm 11$
$13.4 \pm 9.8$
$2.5 \pm 0.2$
$3.5 \pm 0.5$
$1.7 \pm 0.1$ 
References and Notes

1. M.D. Swaine, D. Lieberman, F.E. Putz, J. Trop. Ecol. 3, 359 (1987).

2. Most forest censuses cover a single hectare or less and include only larger trees. Except in Europe and North America, such small samples capture less than half the local species, with many represented by a single individual.

3. N. Pitman, J. Terborgh, M.R. Silman, P. Núñez V., Ecology 80, 2651 (1999).

4. N.L. Stephenson, P.J. van Mantgem, Ecol. Lett. 8,524 (2005).

5. O.L. Phillips, P. Hall, A.H. Gentry, S.A. Sawyer, R. Vásquez, Proc. Natl. Acad. Sci. U.S.A. 91, 2805 (1994).

6. D. Tilman, Plant Strategies and the Dynamics and Structure of Plant Communities (Princeton Univ. Press, Princeton, N.J., 1988).

7. S.W. Pacala, M. Rees, Am. Nat. 152, 729 (1998).

8. B.M. Bolker, S.W. Pacala, C. Neuhauser, Am. Nat. 162, 135 (2003).

9. M. Rees, R. Condit, M. Crawley, S. Pacala, D. Tilman, Science 293, 650 (2001).

10. J.S. Clark, J. Mohan, M. Dietze, I. Ibañez, Ecology 84, 17 (2003).

11. M.B. Bonsall, V.A.A. Jansen, M.P. Hassell, Science 306, 111 (2004)

12. J.S. Clark, S. LaDeau, I. Ibañez, Ecol. Monogr. 74, 415 (2004).

13. D. Tilman, Proc. Natl. Acad. Sci. U.S.A. 101, 10854 (2004).

14. P.J. Grubb, Biol. Rev. Camb. Philos. Soc. 52, 107 (1977).

15. S.J. Wright, Oecologia 130, 1 (2002).

16. J. Silvertown, Trends Ecol. Evol. 19, 605 (2004).
17. Table 1 includes 4,956 species, but some occur at more than one site, and taxonomy has not been fully aligned across sites. We estimate 4,500 different species at the 10 sites.

18. R. Condit, Trends Ecol. Evol. 10, 18 (1995).

19. The Sarawak plot covers 52 ha. For comparison, the number 1,167 was taken from a 50-ha subset. 20. J.K. Vanclay, J. Trop. For. Sci. 4, 15 (1991).

21. R. Condit, S. P. Hubbell, R. B. Foster, Ecol. Monogr. 65, 419 (1995).

22. A. Gelman, J. B. Carlin, H. S. Stern, D. B. Rubin, Bayesian Data Analysis (Chapman and Hall, Boca Raton, Florida, 1995).

23. M. Liermann, R. Hilborn, Can. J. Fish. Aquat. Sci. 54, 1976 (1997)

24. The rate constant $m$ is the derivative of population size $N$ with respect to time, $\frac{\underline{N}}{d t}$, due to mortality alone. It is approximated by $\frac{\Delta V_{z}-\operatorname{lnV}_{3}}{t_{2}-t_{2}}$. Rela-

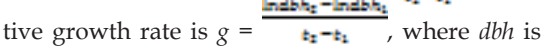
the stem diameter at breast height.

25. Materials and methods are available as supporting material on Science Online.

26. R. Sukumar, H.S. Suresh, H.S. Dattaraja, N.V. Joshi, in Forest Biodiversity: Research and Modeling, F. Dallamier, J. Comiskey, Eds. (Smithsonian,Washington, DC, 1998), pp. 495-506. 27. R. Condit et al., Phil. Trans. R. Soc. London Ser. B 354, 1739 (1999). 28. S.J. Wright, H.C. MullerLandau, R. Condit, S.P. Hubbell, Ecology 84, 3174 (2003).

29. S.P. Hubbell, Ecology, in press.

30. Errors in $d b h$ measurements are 1 to $2 \mathrm{~mm}$ in saplings, and many saplings show slight negative growth (25). We, thus, cannot measure relative growth rates below about $0.5 \%$ year ${ }^{-1}$. Where close to $0.5 \%$ year $^{-1}$, the low end of the sapling growth distributions are probably artifacts. In larger trees, errors are smaller relative to $\mathrm{dbh}$, eliminating the problem.

31. Analyses were supported by NSF grant DEB9806828 of the Research Coordination Network Program to the Center forTropical Forest Science. Data collection was funded by many organizations, principally the NSF, Andrew W. Mellon Foundation, Peninsula Community Foundation, SmithsonianTropical Research Institute, Arnold Arboretum (Harvard), Indian Institute of Science, Forest Research Institute of Malaysia, Royal Thai Forest Department, National Institute of Environmental Studies (Japan), and John D. and Catherine T. MacArthur Foundation. We thank the hundreds of field workers who have measured and mapped trees.

Supporting Online Material : www.sciencemag. org/cgi/content/full/1124712/DC1

Materials and Methods

Figure S1

Tables S1 to S4

References

Database S1

Computer Codes

Article history: January 9, 2006; accepted May 31, 2006; published online June 8,$2006 ; 10.1126$ / science.1124712

Include this information when citing this paper. 